\title{
Mental Health Issues of Muslim Americans
}

\author{
Abdul Basit, PhD, and Mohammad Hamid, PhD \\ Hamdard Center for Health and Human Services \\ Chicago, Illinois
}

\begin{abstract}
The underpinning of all research leading to various schools of thought in the field of psychiatry and psychology is without doubt a product of Western professionals who represent the religio-cultural traditions, historical symbols, and narratives of Western society. Also, the major schools of psychotherapy emerged during an era of individualism and logical positivism reflecting the religious, ethical, and cultural heritage that has shaped the modern Western society. Consequently, the methods and techniques developed in the West may not be always suitable and effective for Muslim Americans. To respond to the growing needs of psychiatric problems encountered by Muslim Americans, many community social service centers have been established in the United States during the past two decades. We now have a growing body of research data suggesting how to tailor our field to the specific needs of this population. We will discuss what kind of emotional and psychiatric problems are most prevalent in Muslim Americans and explain the therapeutic approaches mental health professionals have used and the treatment strategies which have been found effective in the psychosocial rehabilitation of Muslim Americans.
\end{abstract}

Key words: Mental health, Muslim Americans, cultural sensitivity.

\section{Introduction}

$\mathrm{T}$ he concept of the "psychic unity of mankind" 1 has helped us to apply psychiatric theories, research findings, and rehabilitation techniques developed in one cultural setting (the West) to clients immersed in another culture. During the past three decades, however, research findings from cross-cultural psychiatry have demonstrated that individuals' beliefs regarding health and sickness are deeply rooted in the socio-cultural traditions shared

Dr. Basit is a former director of the Multicultural Mental Health Services at the University of Chicago, Illinois. Dr. Hamid is a cofounder and chairman of the Board of Hamdard Center for Health \& Human Services, Chicago, Illinois. Correspondence should be directed to

Abdul Basit, PhD abasit200@gmail.com by members of their social network..$^{2-4}$ A proper understanding of these differences is, therefore, crucial for clinical assessment, diagnosis, treatment, and conducting research.

Clinicians trained in the West must be wary of applying unfiltered assessment methods and therapeutic techniques to Muslim Americans. As early as 1985, Casas, a leading critic of European based psychological models, made the following observations: (a) current knowledge in behavioral science has relied heavily on conceptually biased research paradigms that address ethnic minorities from a pathological, deviant, and culturally deficient perspective; (b) not enough valid and reliable research has been conducted; often conclusions are simply based on anecdotes and unsubstantiated by any data; (c) researchers have tended to overlook the tremendous heterogeneity that exists within the racial ethnic minority groups. ${ }^{5}$ Since the majority in the United States, Europe and Australia comprises a group of 
people who control the economy and political power in the world, their cultural (Judeo-Christian) value system is deemed by its members to be the model value system for the minority to follow. ${ }^{6}$ Value differences play a significant role in assessment and treatment strategies. The markedly different value system of the client and the treating clinician can lead to misunderstanding, mistrust, and ineffective treatment.7-11

\section{Why Introduce a New Perspective?}

It has been observed that that almost all theories and data related to contemporary psychology have come from Western populations. Triandis, who received an award for his distinguished contributions to the international advancement of psychology, stated that almost all theories and data of contemporary psychology come from Europeans, North Americans, Australians, and other Westerners; however about 70 percent of the world's people live in non-Western cultures.12,13 Browning also pointed out that the various hypotheses and theories, based on the research done in the field of behavioral science, cannot claim to be culture-free as people would like to believe. ${ }^{14}$ He further explained that our so-called secular disciplines are never quite as secular as we think. Actually our thinking starts from somewhere and not from absolute objectivity. Our images of what it means to be human are formed first of all by our religio-cultural traditions.

Whether or not people realize it, once they pass judgment on the conduct or behavior of an individual as good or bad, healthy or sick, progressive or retrogressive, useful or dangerous, normal or abnormal, they are using a yardstick of religio-cultural heritage where certain value systems have been determined to be superior to others. ${ }^{15}$ Western psychiatry naturally reflects the religio-cultural heritage that shaped Western society and does not always reflect the socio-cultural traditions of Muslim Americans. Also, the use or application of therapeutic techniques developed by Western scholars may not be always suitable. It is therefore necessary that Muslim professionals, especially mental health workers, do not uncritically accept Western ideas and constructs in behavioral science.

\section{Elements of Cultural Syndrome}

Triandis attempted to highlight the differences between various cultures by introducing the concept of "cultural syndromes." 16 He identified the following cultural syndromes to illustrate his viewpoint:

1. Tightness: In some cultures minor deviations from accepted norms are criticized, and those who deviate may be punished, while in other cultures only major deviations from norms are criticized. One can easily discern this tendency of tightness in many Asian countries.

2. Cultural Complexity: Certain cultures are more complex due to a multiplicity of religious, economic, political, educational, and social standards.

3. Active-Passive: Certain cultures are characterized by fierce competition, and many people are eager to take the lead. In other cultures cooperation and allowing others to lead are acceptable.

4. Honor: In certain cultures, defending one's honor becomes an overriding factor. Moreover, community members favor the use of aggression to defend one's honor.

5. Collectivism: In some cultures personal goals are very often subordinated to those of the family or tribe. Other communities prioritize personal goals over those of the family and community. Many critics believe that the glorification of individual rights has been overemphasized in Western cultures.

6. Vertical and Horizontal Relationship: In some cultures hierarchy is very important, while in other cultures social behavior is more egalitarian.

Corsini also stated that Western psychologists might have underestimated the therapeutic techniques used in Asian cultures. ${ }^{17}$ According to him, psychotherapies address three major levels of health and development: pathological, existential, and transpersonal. In addition, he asserts that therapists in Asian cultures focus more on the existential and transpersonal levels and less on the pathological level. One must emphasize the need for recognition of cross-cultural implications in treating nonWestern clients for it would be counter-productive and nontherapeutic to treat non-Western patients as individuals outside of their family and community contexts.

It is therefore imperative to have a clear understanding of these religio-cultural differences and social customs and values when conducting an assessment or psychotherapy within minority communities. 
Most Prevalent Mental Health Issues in American Muslim Communities

Unfortunately, there is a dearth of data in this area. The reason is simple. Only during the past three decades has some attempt been made to provide mental health services tailored to the specific socio-cultural needs of Muslim Americans of various ethnic backgrounds. Only a few treatment centers provide a full range of services. Due to these limitations, we have data available from two sources that we consider reliable. Table 1 shows the psychiatric diagnoses of Muslim Americans, primarily of South Asian ethnicity, but also Middle Eastern and Bosnian ethnic backgrounds. The data are based on 875 clients seen at the Hamdard Center for Health and Human Services in the Chicago area. Table 2 shows the emotional and behavioral problems of young Muslim Americans, based on the data Dr. Abdul Basit collected with the help of the Islamic Society of North America (ISNA) after September 2001 from various private Muslim social service agencies in Illinois, Michigan, Missouri, Virginia, and Kentucky. This study was based on a federal grant by the National Mental Health Information Center of the Substance Abuse and Mental Health Services Administration (SAMHSA).

Table 1 presents a brief discussion of the data. A sharp contrast exists when we compare the prevalence of psychotic disorders among our group (5 percent) and the data available for Euro-Americans (12.7 percent), Latino Americans (17.6 percent), or Southeast Asian Americans (22.4 percent). ${ }^{3}$ Also, our data do not support the widely accepted hypothesis that South-Asian Americans tend to somatize their psychological problems and thus transform their mental health problems into physical complaints. Adjustment disorder is 43 percent, which is understandable because South Asian Americans have to go through a process of adaptation, acculturation, and integration, all of which may give rise to issues related with adjustment disorder. Substance abuse is only 4 percent; this would indicate that the clinicians working with South Asians have not encountered drug abuse issues very often.

A review of the data in Table 2 reveals that the highest reported category for Muslim adolescents was adjustment disorder. This certainly confirms the general impression of Muslim clinicians that young Muslim Americans experience difficulty trying to
Table 1. Intake Diagnoses of Muslim Americans at Hamdard Center for Health and Human Services, Chicago $(\mathrm{N}=875)$
Diagnosis

Adjustment Disorder

Anxiety Disorder

Mood Disorder

Obsessive Compulsive Disorder

Post Traumatic Stress Disorder (PTSD)

Schizophrenia and other

Psychotic Disorders

Substance Abuse

Table 2. Emotional and Behavioral Problems of Young Muslim Americans ( $\mathrm{N}=712$; Mean Age: 14.9 years)*

\section{Diagnosis}

ADHD

Mood Disorder

Anxiety Disorder

Schizophrenia

Adjustment Disorder

Alcohol and Substance Abuse

Impulse Control Disorder

Eating Disorder

Somatoform Disorder

Other Issues**
$43 \%$

$15 \%$

$9 \%$

$14 \%$

$10 \%$

$5 \%$

$4 \%$
Percent
* After September 11, Dr. Basit collected the data on young Muslims with the help of ISNA from various Muslim Social Service agencies in Illinois, Michigan, Missouri, Virginia, and Kentucky. This study was commissioned by the Center for Mental Health Services (CMHS), Substance Abuse and Mental Health Services Administration (SAMHSA).

** Other issues include victimization, trauma, domestic violence, and cultural conflicts.

resolve conflicting value systems. Problems in the area of attention deficit and hyperactivity disorder (ADHD) were the second most frequently reported problem at 16.5 percent. We, however, seriously doubt whether this figure really represents the true picture, because many psychologists and psychiatrists have raised serious concerns about the issue of 
overdiagnosis in this category. ${ }^{18}$ Violent behavior at home, at school, or in the community is just 5 percent, and drug abuse is only 3 percent. These figures in the area of violent behavior and drug abuse are surprisingly low, especially when compared with Euro-Americans.

The data presented in Table 1 and Table 2 are based primarily on the clients who went to Muslim Mental Health or Social Service Centers to seek help. Therefore, since they reflect treated prevalence, they do not reflect prevalence in the community. Given this, we cannot claim this reflects the clinical picture of all Muslim adults or youths in America. We must emphasize that the figures given for other ethnic-cultural groups of Americans are based on epidemiological studies. ${ }^{3}$

\section{Major Impediments in Treating Muslim Americans}

Studies on ethnic minorities have consistently pointed out that even when mainstream agencies offer a full complement of mental health programs, they are significantly underutilized or not utilized at all by ethnic minorities, including African-American and Hispanic clients. Our data further substantiate these findings. Some of the major impediments that South Asian and other Muslim Americans face when seeking help for mental health problems follow:

1. The lack of understanding and awareness about mental health issues by these groups is a major drawback.

2. Difficulty in speaking and understanding English tends to be another barrier.

3. The lack of familiarity with the concept of counseling or psychotherapy poses major problems in the treatment of clients.

4. Many clients have strong reservations about modern psychiatry, and some still seek out traditional healers

5. The lack of culturally competent mental health professionals further compounds the problems of assessment and treatment.

6. Issues of social stigma and family honor prevent many clients from seeking treatment.

\section{Effective Therapeutic Approaches}

Muslim mental health professionals and community activists in America's South Asian communities have realized that these impediments discourage Muslim clients from seeking professional help, caus- ing them and their families to suffer unnecessarily and possibly even allowing their mental health problems to become unmanageable. Precisely because of these concerns, Chicago's Hamdard Center for Health and Human Services and other agencies with similar missions were established. Based on our extensive experience with Muslim Americans and with the general population, we feel confident in stating that the following therapeutic approaches have been found to be most effective when dealing with Muslim American clients:

1. A more active and structured approach with clients is effective. A nondirective approach, such as the one proposed by Carl Rogers in 1951, will not work. ${ }^{19}$

2. It is vital to educate clients about the nature and purpose of psychotherapy. Therapists must explain and illustrate how psychological and emotional stresses can produce anxiety and depression.

3. In the early stages of counseling, after clients have developed the therapeutic relationship, they expect, and sometimes demand, frequent access to the therapists.

4. Sometimes clients expect therapists to help them resolve many other problems that might be unrelated to their mental health issues. Therapists must respond to these requests in a sympathetic manner.

5. Rehabilitation of clients is more effective when done within the natural fabric of the client's own community.

6. In comparison to the Euro-American community, a more aggressive community outreach is required in the Muslim American community.

7. When clients have the support of their family, friends, and community (e.g. community centers and religious leaders), the outcome of the treatment is positive and lasts longer.

\section{Recommendations and Conclusions}

One cannot overemphasize the pressing need to establish more multicultural and multilingual centers that are tailored to address the mental health problems of Muslim American communities. Muslim American clinicians must revise current assessment tools to make them language appropriate and culturally sensitive. We recommend that more research is needed to show how mental health issues of Muslim Americans of various ethnic backgrounds differ from 
and how they are similar to those of their nonMuslim counterparts in those ethnic groups. In addition, it must be stated that not all Muslim American families are religious and traditional. Some Muslim families are intact, while others are not due to divorce or separation. Some Muslim American families live in extended families, and some live as nuclear units. No research has been conducted to show how these different family structures affect the type of stress encountered, generate conflicts, or affect the support network available. While considerable research has been done to understand and explain the problems of the acculturation process and its possible impact, almost no data exist to determine what special problems confront Muslim Americans. It is worth exploring whether religious and socio-cultural factors have been major impediments to integration and why some people develop chronic ethnic-identity problems and others do not.

\section{References}

1. Boas F. The mind of primitive man. New York: Macmillan; 1911.

2. Segall MH. Human behavior in global perspective: an introduction to cross-cultural psychology. Boston: Allyn and Bacon; 1990.

3. Uba L. Asian Americans: personality patterns, identity, and mental health. New York: Guilford Press; 1994.

4. Triandis HC. Culture and social behavior. New York: McGraw-Hill; 1994.

5. Casas JM. A reflection on the racial/ethnic minority research. Couns Psychol. 1985;13: 581-98. http://doi.org/g73

6. Ponterotto JG, Casas JM. Handbook of racial/ethnic minority counseling research. Springfield, IL: Charles C. Thomas; 1991.

7. Kinzie JD, Tseng W. Cultural aspect of psychiatric clinic utilization: a cross-cultural study in Hawaii.
International Journal of Social Psychiatry. 1978;24:177-88. http://doi.org/g7j

8. Kuo WH. Prevalence of depression among AsianAmericans. J of Nerv Ment Dis. 1984;172:449-57. http://doi.org/g74

9. Sue S, Zane N. The role of culture and cultural techniques in psychotherapy: a critique and reformulation. Am Psychol. 1987;42:37-45. http://dx.doi.org/10.1037/0003-066X.42.1.37

10. Kaneshige, E. Cultural factors in group counseling and interaction. Pers Guid J. 1973;51:407-12.

11. Kinzie JD. Cultural aspects of psychiatric treatment with Indochinese refugees. Am J Soc Psychiatry. 1985;5:47-53.

12. Triandis HC. Collectivism and individualism as cultural syndromes. Cross-Cultural Research. 1993;27:55-180. http://doi.org/g78

13. Award for distinguished contributions to the international advancement of psychology. Am Psychol. 1995;50:260-5. http://dx.doi.org/10.1037/0003-066X.50.4.260

14. Browning DS, Miller-McLemore BJ, Couture PD, et al. From culture wars to common ground: religion and the American family debate. Louisville, KY: Westminster John Knox Press: 1997.

15. Basit, A. Conflicting value systems and therapeutic intervention. Hosp Community Psychiatry. 1973;24:174-5. PubMed PMid: 4686900

16. Triandis, H.C. The psychological measurement of cultural syndromes. Am Psychol. 1996;51:407-15. http://dx.doi.org/10.1037/0003-066X.51.4.407

17. Corsini RJ, Wedding D. Current psychotherapies. Itasca, IL F.E. Peacock Publishers, Inc., Itasca, IL; 1995.

18. Basit A. Attention deficit/hyperactivity disorder: are we fostering over-diagnosis? J Islam Med Assoc. 2007;39:58-64. http://dx.doi.org/10.5915/39-2-6512 19. Rogers CR. Client-centered therapy. Boston: Houghton Mifflin; 1951. 